\title{
Sudden cardiac arrest in Belgrade emergency medical technician occurring at workplace - a brand new case
}

\author{
TIANA PETROVIĆ ${ }^{1}$, RADOJKA GLAMOČLIJA-PETROVIĆ ${ }^{1}$, ALEKSANDAR \\ OKILJEVIĆ ${ }^{1}$ SLAĐANA ANĐELIĆ ${ }^{1}$, SANJA PETROVIĆ PAJIĆ \\ 1 Emergency Medical Services, Belgrade, Serbia \\ 2 Clinical centre of Serbia, Belgrade, Serbia
}

Corresponding author

Slađana Anđelić

Franše d'Eperea 5, 11000 Belgrade, Serbia

Phone: +381641245757

E-mail:novizivot94@gmail.com

Key words: sudden cardiac arrest, medical technician, EMS, workplace

Sudden cardiac arrest (SCA) is always an important topic, which catches physicians and health professionals' attention. According to the Occupational Safety and Health Organization, $15 \%$ of workplace fatalities are due to SCA. While the incidence of SCA among employees in other Emergency services, i.e. firefighters (1) and police (2) has been described in the literature, there are no recorded data or published studies about SCA among medical staff employees in Emergency Medical Services (EMS). We describe the rare case SCA in emergency medical technicians (EMT) while in workplace.

A 51-year-old EMT was examined at the EMS ambulance during his working hours, because of acute burning pain behind the sternum, radiating to the left shoulder and elbow and sweating. A longtime athlete, but also a passionate smoker (over 20 years, around 30 cigarettes per day). Hypertonic, working in shifts in a field medical team for more than 25 years. His father had suddenly died at 60 years of age. On examination: conscious, oriented, eupneic, acianotic, afebrile, overweight, neck veins not pronounced, no murmur on carotid arteries. Blood pressure (BP) on arms $160 / 100 \mathrm{mmHg}$, pulse $100 / \mathrm{min}$, respiratory rate, 18 breaths/minute, oxygen saturation $(\mathrm{SaO} 2)$ was $98 \%$. A 12-lead ECG showed sinus rhythm, qR in D1 and aVL, RR' in D3, flattened T in AVL (figure 1). During observation and continuous ECG monitoring, VF cardiac arrest occurred. Cardiopulmonary resuscitation (CPR) was conducted according to 2015 shockable rhythm guidelines. Return of spontaneous circulation, breathing and conscious- ness was achieved 8 minutes later. Hemodynamically stable, the patient received a dual antithrombotic therapy and was transported directly to the heart catheterization lab with continuous monitoring. At coronography (figure 2), a $100 \%$ stenosis was observed on D1 branch (Rentrop 0 , TIMI 0), after which angioplasty was performed. Two months later, the EMT returned to work as a dispatcher in the Department of Transportation and Dialysis of EMS Belgrade.

The first academic report on SCA among Chinese doctors was published in 2015. (3) Chronic exposure to established risk factors for CVD (hypertension, dyslipidemia obesity, and tobacco smoking), as in our patient, can lead to underlying coronary heart disease, providing the pathophysiologic substrate for acute sympathetic arousal and cardiovascular strain to precipitate acute cardiovascular events, including SCA . (4) It is thought that stress triggers the final steps in a pathophysiologic cascade, culminating in an acute cardiovascular event. Bajić- Dragutinović Ž et al. examined the link between cardiovascular risk factors, shift workers and duration of service in Belgrade EMS. (5) The leading factor was workplace stress, shift work ${ }^{3} 20$, as well as smoking. Our patient had all of the abovementioned risk factors.

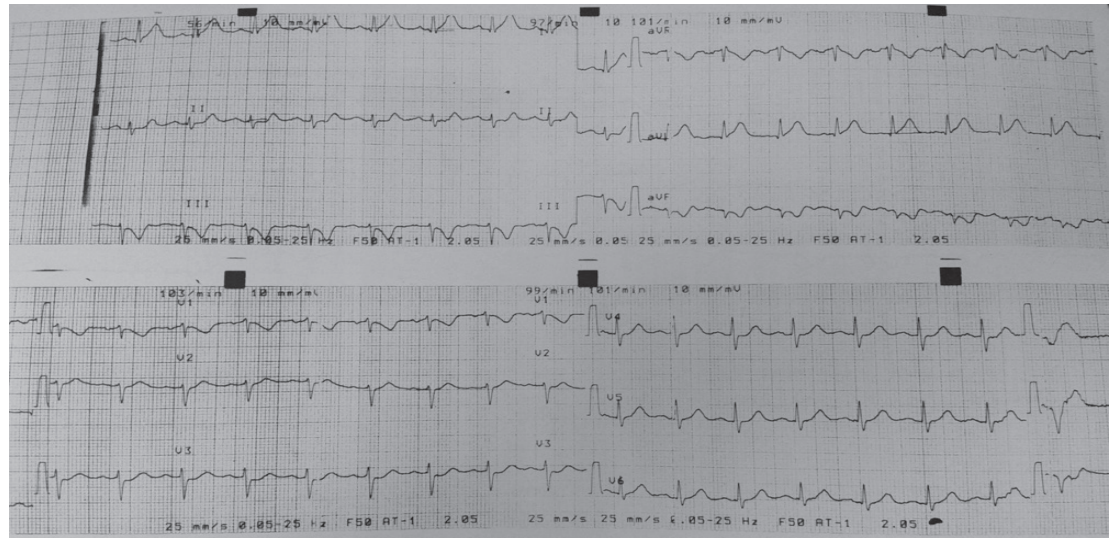

Figure 1. ECG finding
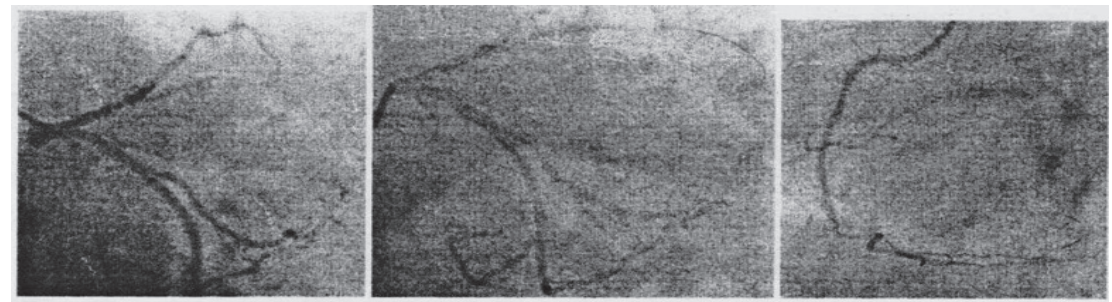

Figure 2. Coronary angiography finding 
SCA is a life-threatening condition that can happen to anyone, anytime, anywhere, and at any age. Due to increased stress, gency medical workers are a trigger group existing risk factors and shift work, emer- for SCA in the workplace.

\section{REFERENCES}

1. Patterson PD, Smith JK, Hostler D. Cost-effectiveness of workplace wellness to prevent cardiovascular events among U.S. firefighters. BMC Cardiovasc Disord 2016;16:229.

2. Varvagiou V, Farioli A, Koree M, Sato S, Dahabreh IJ, Kales NS. Law enforcement duties and sudden cardiac death among police officers in United States: case distribution study. BMJ 2014;349:g6534.

3. Song XN, Shen J, Ling W, Ling HB, Huang YM, Zhu MH, et al. Sudden deaths among Chinese physicians. Chin Med J 2015;128:325153.

4. Zimmerman FH. Cardiovascular disease and risk factors in law enforcement personnel: a comprehensive review. Cardiol Rev2012;20:159-66.

5. Dragutinović-Bajić Ž, Petrović S, Anđelić S. The link between cardiovascular factors, shift workers and duration of service in emergency medical services. NČ urgent medicin HALO 194, 2017;23(3):127-37. 